\title{
Michel Arouimi, Rimbaud malgré l'autre. [Re]lire Rimbaud
}

\section{Mario Richter}

\section{(2) OpenEdition}

1 Journals

\section{Edizione digitale}

URL: http://journals.openedition.org/studifrancesi/555

DOI: 10.4000/studifrancesi.555

ISSN: 2421-5856

\section{Editore}

Rosenberg \& Sellier

\section{Edizione cartacea}

Data di pubblicazione: 1 aprile 2015

Paginazione: 180-181

ISSN: 0039-2944

\section{Notizia bibliografica digitale}

Mario Richter, « Michel Arouimi, Rimbaud malgré l'autre. [Re]lire Rimbaud», Studi Francesi [Online], 175 (LIX | I) | 2015, online dal 01 avril 2015, consultato il 18 septembre 2020. URL : http://

journals.openedition.org/studifrancesi/555; DOI : https://doi.org/10.4000/studifrancesi.555

Questo documento è stato generato automaticamente il 18 settembre 2020.

\section{(c) (i) $\odot$}

Studi Francesi è distribuita con Licenza Creative Commons Attribuzione - Non commerciale - Non opere derivate 4.0 Internazionale. 


\title{
Michel Arouimi, Rimbaud malgré l'autre. [Re]lire Rimbaud
}

\author{
Mario Richter
}

\section{NOTIZIA}

MICHEL AROUIMI, Rimbaud malgré l'autre. [Re]lire Rimbaud, Lyon, Jacques André éditeur, 2014 , pp. 194.

1 Rimbaud continua a suscitare l'attenzione della critica e sembra anche sollecitare i più diversi e singolari modi di leggerlo e di valutarlo. Ecco dunque che anche Michel Arouimi, già noto per avere recentemente indagato a modo suo sulle "réminiscences" di Rimbaud in Ramuz e in Bosco, adesso si impegna a rintracciare anche quelle che il poeta di Charleville avrebbe tratto da Victor Hugo, in particolare da L'Homme qui rit (1869) e in parte dal Poe della novella fantastica The Fall of the House of Usher, tradotta da Baudelaire. L'impegno critico di Arouimi scarta programmaticamente la cultura che orienta gli studi attuali, specie quelli universitari, una cultura che si è sviluppata sulla base delle regole fondamentali che positivismo e storicismo hanno elaborato e trasmesso al secolo scorso, specialmente per quanto riguarda lo studio delle "fonti". Ponendosi al di fuori e anche contro ogni attuale metodo di critica letteraria, l'A. si sente in tal modo del tutto dispensato dal sapere che cosa prima di lui si è detto sul suo stesso argomento di studio. Così, ad esempio, non dice una sola parola sull'Homme juste, né si esprime sull'esame che a questo testo ha dedicato Yves Reboul (cfr. Parade sauvage, $2,1985)$ per riconoscere in termini del tutto convincenti nell'“uomo giusto" proprio Hugo (e non Gesù Cristo come si è a lungo creduto). Appoggiandosi invece sull'autorità di Ernst Jünger, citato due volte, Arouimi non esita ad attaccare frontalmente l'attuale realtà culturale che si ritiene fondata sulla tecnica e sulla globalizzazione. Occorre dire che, come di solito avviene di fronte alle novità, si prova un certo disagio e quasi un senso di rifiuto a seguire un tipo di critica dal carattere programmaticamente emozionale e psicologico come quella qui praticata dall'A. 
2 Senza volerci qui soffermare sulle varie argomentazioni alle quali Arouimi ricorre per provare l'influenza esercitata da Hugo (nello sfondo c'è anche Poe) sull'inconsapevole Rimbaud, ci limitiamo a riportare alcune sue frasi che possono dare un'idea sufficientemente precisa del risultato essenziale di un'indagine fondata sul riconoscimento delle "strutture mentali" e dell' "effluvio": «...la plume de Rimbaud paraît se livrer à la fusion des détails similaires qui font une sorte de lien entre ce chapitre "Résidu" [del romanzo L'Homme qui rit di Hugo] et le poème de Roderick, dans La chute de la maison Usher [di Poe]. Sans doute ce poème comme ce chapitre, dans leurs grandes lignes et dans leur imagerie, témoignent-ils de structures mentales qui perdurent dans les œuvres d'art, depuis des temps immémoriaux. Mais sous la plume de Rimbaud, le nom d'Edgar Poe et celui de Hugo recouvrent des problèmes qui dépassent le cadre, pourtant si large, de cette survivance [...] La fumée comme l'effluve, sont les métaphores, dépréciative ou valorisante, d'un art d'écrire [celui de Hugo] quasi magique, dont Rimbaud aurait été la victime privilégiée [...] Le public moderne, surtout universitaire, n'est pas enclin à adopter ce point de vue métaphysique [...] Le verbe poétique, avec les ombres qu'il doit à sa nature humaine, agirait sur un destin particulier, comme le Verbe sur les destins humains, régis par des lois, des mesures, dont le Verbe ne fait que nommer le mystère» (pp. 171, 188, 189, 190).

3 Nonostante le perplessità che queste affermazioni suscitano in chiunque concepisca lo studio delle "fonti" in termini di positività logico-storica, non si può affermare che le interpretazioni di Arouimi siano prive di una loro peculiare suggestione, che è comunque di natura più poetica che critica. Si tratta infatti di un autore capace di scrivere con abilità e sottigliezza, rivelandosi anche pacificamente consapevole del carattere delirante della sua ricerca. 